\title{
MODELLING SUSTAINABILITY FOR A GREEN CIRCULAR ECONOMY
}

\author{
Yury Zhukov and Marianne Cherrington
}

\section{INTRODUCTION}

While we are trying to survive the multitude of social, health, and economic issues brought about by the Coronavirus pandemic, it is easy to forget that before governments started issuing lockdown orders, closing borders, and engaging in massive political battles, the world had been beset by other risks. The global risk reports written by the World Economic Forum have always been a valid, albeit slightly delayed identification of the most impactful and relevant risks that affect the world. The latest report, published in January 2020, demonstrated a dramatic increase in environmental risks ranked in the top ten (World Economic Forum, 2020a, p. 102). These included increased likelihood of climate action failure, biodiversity loss, extreme weather, natural disasters, and human made environmental disasters. The water crisis was classified as a social risk, but could equally be added to the environmental list (Figure I).

TOP 10 RISKS OVER THE NEXT 10 YEARS

\section{Long-Term Risk Outlook: Impact}

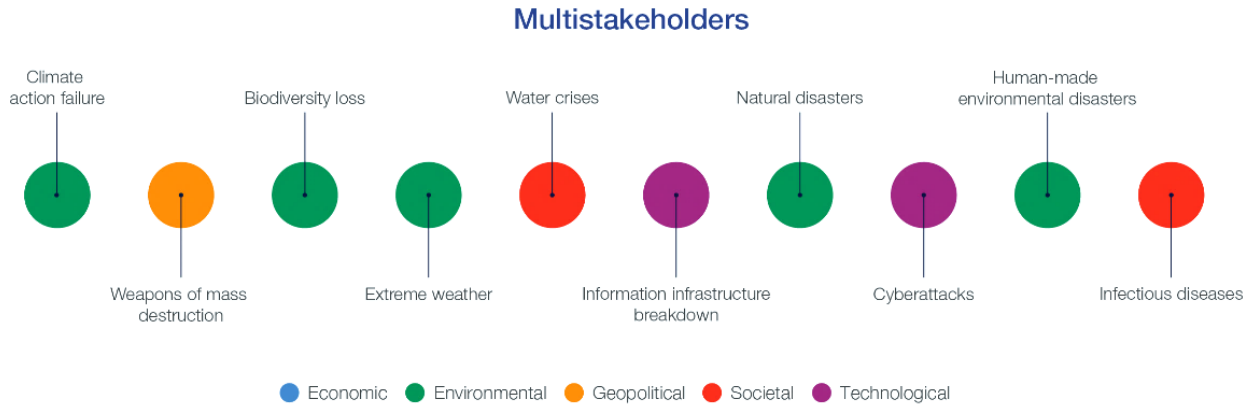

\section{Global Risks Report 2020}

Figure I. Long-term Risks Outlook Impact, (World Economic Forum, 2020b).

With this shift in global risk perception and appreciation of the economic consequences of climate action, sustainability professionals are valued in the labour market; it is a viable career option. Otago Polytechnic Auckland International Campus (OPAIC) is an institution that aspires to produce New Zealand's most employable graduates; we must further integrate sustainable practices and sustainability related skill sets and projects into programme delivery structures. 


\section{NEW MINDSETS FOR A GREEN CIRCULAR ECONOMY}

At the heart of the circular economy lies the principle of system design that phases out the need to introduce new materials into production cycles, thus reducing the impact of economic activity on the environment (Ellen MacArthur Foundation, 2017). The design loops can be relatively simple, like the reusable cups at Auckland Zoo which eliminate the need for single-use takeaway cups (Healy, 2019), or complex product stewardship programmes, like the one being implemented by Fuji Xerox New Zealand (Shareef \& Harding, 2019), and even making the whole waste management process in cities circular to eliminate waste and accumulating landfills (Blick \& Comendant, 2018). This is likely to significantly reduce many costs associated with waste management and introduction of new resources and components into the equation. It has the potential of being implemented in a variety of business settings from the technology sector to dairy farming.

The process of switching businesses to a circular model is a long one and requires a redesign of supply chains and re-evaluation of production models. It requires a combination of business acumen and technical knowledge. Probably the most difficult element is creating a far-sighted mindset that does not just try to fix the old system, but disrupts and therefore revamps the model, redesigning the way we consume and service products. That shift requires a combined effort in businesses, government institutions, and also an effort on the part of consumers. That is exactly why introducing the circular economy as a key element in determining business' future development strategies, via case studies in a variety of subjects, is important. Sustainable system design is likely to be an important employment path in the future, in whatever industry it is applied.

\section{LEARNING TO MANAGE A CIRCULAR ECONOMY PROJECT}

The concept of the circular economy has been introduced in a variety of OPAIC courses in the undergraduate programme, although implementation is still in the early stages. Specifically, in Project Management Level 5 the students need to create a project plan for one of the potential projects recommended to them. The students are required to create a project plan for one Countdown store, setting up a collection point for glass Coca-Cola bottles and sending them back to the Coca-Cola Amatil plant to be reused. The first result of students working on this project was a well thought through plan that included budgeting for the initial setup costs and the costs of running the project for three months as a trial run.

Economic viability of the project had to be considered as part of the project planning exercise. While the economic viability of this project run in a single store left much to be desired (the initial setup and three-month operating costs amounted to $\$ 7106$ ), the students did specify that economies of scale were critical and if extended to all the Countdown stores, the project would have been economically attractive.

While it is a relatively simple project to design and create a provisional budget, it sparks the understanding of synergies between different industries and how initiatives in one industry could impact the availability of resources in another. While this is yet to be implemented in Project Management courses at higher levels, there is a clear pathway for developing complex and meaningful assignments at lower levels that can potentially lead to interesting industry projects.

Another two Level 7 papers that could benefit significantly from being included in a continuity that encourages sustainable solutions are Strategic Management and Contemporary Issues in Organisations. They create a synergy that can lead to students developing their interests in the latter and producing a viable circular strategy for the company of their choice in the former. At the moment, the authors are working with a group of students who started their Graduate Diploma in Applied Management programme in OPAIC four terms ago. The lockdown created an interruption to their studies, but they were some of the first students to be introduced to the concept of the circular economy as part of the Contemporary Issues class; they made viable attempts at suggesting sustainable solutions to existing companies. 
One example in particular stood out, it was a case study exploring the concept of cotton fabric collection and recycling that could be implemented by a major clothes brand. The student specifically created a flowchart that connected Salvation Army, Red Cross, Habitat for Humanity and City Mission (collecting unusable cotton clothes) to Icon Textiles (recycling old clothes into usable yarn) and, finally, to Kathmandu (making clothes out of recycled cotton yarn). The assignment went into significant detail on the process of actual fabric recycling but did not analyse the economic component. Nevertheless, that was one of the more innovative and interesting recommendations detailed in an undergraduate programme. The student was later encouraged to explore the possibility of setting up a fabric collection and recycling system as part of a lower level Project Management course. Unfortunately, the project was not explored further, but it exemplifies a student-driven project that can be successfully pursued across multiple courses, a concept encouraged on campus.

It would have been particularly beneficial to develop the project further in Strategic Management. The course creates a logical continuity if the concept of the circular economy was to be implemented as a go-to strategic methodology. In all fairness, the learning outcomes of the course do mention sustainability as an important element of business strategies, but almost as an afterthought. Students are required to develop strategic recommendations for a real company that they select for research. Students are required to select a company of interest, which should encourage them to try and develop a more intimate understanding of the selected industry. However, we are asking students to suggest improvements to organisational strategies that had been developed by professionals experienced in the application of strategic tools and, hopefully, very knowledgeable about the technical side of the business processes of the selected company. If we rely entirely on traditional strategic tools, we would be asking the students to reinvent a very well documented wheel. The circular economy provides a unique opportunity in this case.

At the moment, the same group of students are completing the Strategic Management course. Lockdown disruption has made it difficult to recommend individual approaches and encourage students to follow through with the idea of the circular economy as a key focus in most of their courses, but the same design encourages the students to explore sustainable solutions implementable in their selected industries; it may result in a continuity for students enrolled in the course.

Multiple companies in New Zealand are already implementing circular strategies; Fuji Xerox has been widely praised for its product stewardship programme, which helped recycle and reuse 99 per cent of returned equipment. However, priorities in the market continue to shift. The desire to be at the leading edge of sustainable strategies, and the circular economy in particular, is likely to be a driver that differentiates the content and method of education in OPAIC, supporting our international students to become some of the country's most employable graduates.

\section{MODELLING OPERATIONS SUSTAINABILITY IN A CLIMATE OF CHANGE}

A case study approach is an important way for students to be current with industry practice, relating real issues to the learning outcomes that they must demonstrate. New metrics of success and performance in business are being created because few companies are invulnerable in the face of creative destruction (Cherrington, 2019). Company attrition rates are escalating; about "half of S\&P 500 companies will be replaced over the next ten years" (Anthony, Viguerie, Schwartz, \& Van Landeghem, 20I8). In Contemporary Issues in Organisations, Air New Zealand is used as a case study. Their Sustainability Framework is aligned to their purpose and Go Beyond Strategy. As the effect of the coronavirus pandemic has hit home, the success of Air New Zealand is "inextricably linked to the success of New Zealand" (Air New Zealand, 2020); their Diversity and Inclusion vision (Downes, 2018) leads Aotearoa into a changing future with a changing workforce (Air New Zealand, n.d.). 
Consumers deserve more - they demand it. Consumers are demanding a holistic and authentic plan for sustainability, because progress, performance or productivity is meaningless alongside 'revolting inequity' (Ardern, 2020, p 29). Greenwashing is being called out. There is so much to learn in the Applied Management programme given the role that companies play in wealth creation. It is no surprise the best-performing companies seem magnitudes away from rivals, especially in the highly unpredictable circumstances we find ourselves in (Frick, 2016).

This generation of leaders and teachers have been indolent. When a 16-year-old can drive a global movement and can logically, fervently and succinctly articulate the case for climate change in less than four minutes, it is a clear indication of systemic disconnect (Thunberg, 2018). This became a talking point in Contemporary Issues in Organisations, where students must analyse and evaluate global data and information for trends that influence industry decision making. Evidently, one learned person can make a difference. It is almost 60 years since Silent Spring; it is a truism that "in nature nothing exists alone" (Carson, 1962). From this point, learning takes on a new relevance; insights form other courses can be integrated and communicated convincingly.

New collaborative models for sustainable operations exist, evolve and must be interwoven into the fabric of what we do and how we do it. Tertiary educators must address global sustainability challenges. Our acts should make a difference to inspire, promote and support change in sustainability across campuses (Australasian Campuses Towards Sustainability, 2020, n.d.). Climate change, resource depletion, and biodiversity loss connect to the choices we make every day and the decisions that direct us. Our young leaders know this; the new mindsets and new futures that tertiary study provides are part of a larger ecosystem of possibility. This connects to the idea of a circular economy.

\section{SUSTAINING AND LEADING AN INDUSTRY FOCUS}

The new Climate Change Response (Zero Carbon) Amendment Act 2019 (Zero Carbon Act), is a framework to attain net zero emissions by 2050. Applied management students must come to terms with how this Act will alter the way in which we do business in Aotearoa and create a context for their studies. Aligning with New Zealand's global commitments under the Paris Agreement, the Zero Carbon Act sets steady, staged reductions of Greenhouse Gas (GHG) emissions. In January 2020, the OPAIC Contemporary Issues in Organisations course shifted from the theme of disruptive innovation to emissions reduction under the Zero Carbon Act. Students were able to choose industries they were most interested in, and explore data to support innovative approaches for organisational action. A poster exhibit was created and a number of presenters came to impart their sustainability perspectives. Beca's Climate Change and Sustainability Advisor, Ben Mayer, highlighted the sustainability career pathway and how Beca is helping clients navigate climate change risk to unlock economic and social opportunities. Carolyn Cox from Sustainable Business HQ revealed how sustainability consulting supported organisations to establish sustainability strategies, leading to competitive advantage. By reflecting on the implications of the new Zero Carbon Act, a plethora of industry presentations were integrated into scaffolded learning. OPAIC construction students were present en masse at our campus events. Energy usage was a favoured assessment topic, so David Cameron-Brown clarified structure and sustainability issues in the New Zealand Electricity Industry. Chlöe Swarbrick, New Zealand Member of Parliament for the Green Party, inspired students to see the big picture in sustainability and to "make themselves part of something bigger, as participation amplifies actions with a sense of purpose."

This is what the Climate Leaders Coalition is doing (Climate Leaders Coalition, n.d.). They are "on a mission to reduce emissions in New Zealand." In just two years, they have grown from a dozen founding signatories to over one hundred leading firms, partnered to inspire business leadership and collective initiatives and strategies around climate change action. As New Zealand transitions to an emission reduction economy, business leaders are seeking to leverage their actions and learn from each other to accelerate processes of change (Climate Leaders 
Coalition, n.d.). Smaller companies can gain advantage as well; the zeitgeist is beginning to shift and initiatives such as Climate-X programmes connect businesses with experts and organisations keen to progress emissions reduction (Climate-X, 2019).

Under the coronavirus lockdown, Contemporary Issues had a new context for the Zero Carbon Act. We had a global experiment in emissions reduction. Both the climate crisis and coronavirus do not respect borders; neither catastrophe is "getting the co-ordinated international response it deserves" (The Economist, 2020, p. 7). Lockdown revealed just what it would take to actually achieve our negotiated emission targets; in order for the Zero Carbon Act to have any bite, policy must mitigate emissions, with lower financial, social and political cost. As the coronavirus changes our behaviours, is it 'back to work' and play as usual? We went 'online' overnight. We zoomed around virtually and flexibly; work-life-balance and working from home were real things. Will we be able to 'embrace the mobile mentality,' reduce emissions and traffic congestions to model the culture that employers utilise as they 'quit their CBD offices'? (Parker, 2020). Are we challenging our students to use these agile methodologies and be articulate enough to co-present their research reports while networking at conferences? Will our most employable students be 'culture ready' so as to be head-hunted by corporates as they graduate?

\section{SPECIALIST SKILLS WITH CAPABILITIES}

Tertiary education should not be 'inaccessible.' It is a stepping stone to a world of possibilities. The learner capabilities in the I am Capable Framework include 'practises sustainably' (Otago Polytechnic, n.d. b), and EduBits sustainability micro-credentials include 'waste recycling', 'lead strategy development' and 'sustainable practice at work' (EduBits, n.d.). OPAIC is particularly good at delivering mini projects, industry projects and internships in undergraduate programmes, and sustainability topics are the perfect conduit to promote the strengths our student researchers possess; they can lead to real change in the companies to which they are seconded.

What is the value of a pricey international qualification with 'the on-campus experience?' Even before COVID-19, tertiary education was unfit and ripe for disruptive innovation. Lack of meaningful change is appalling, especially since education is the easiest means to 'close the inequities gap' that rages across the world (Barclays, 2020). Unprecedented events have forced educators to look soul-deep; will we enliven educational environs, or be replaced (Soul Machines, 2018)?

Let us create vibrant, innovative and connected campuses. Let us get curious and make learning and teaching exciting and meaningful. We know what we do is valuable and relevant, but there is a bigger, untapped need to get real about the wide-reaching wicked problems that scare the bejeebies out of us. Fear and complacency are just an excuse. What we do at work and at home is who we are. Let us truncate all the superfluous and deliver holistically; that is the kaupapa in New Zealand, never more relevant. It is not rocket science, but if that is what motivates you, we do that here in New Zealand too, and Rocket Lab is hiring (Rocket Lab, 2020)!

\section{CONCLUSIONS}

It has become apparent that the contexts in which Applied Management qualifications are delivered keep morphing at record pace. As we labour to create New Zealand's most employable graduates, the recurring theme of sustainability confronts us every day. Sustainability is not a separate course, soon forgotten; it holds the key to learning that is creative, innovative, tech-savvy and rewarding. Considering the urgency and scale of the climate change catastrophe, it is imperative that we step beyond recognising environmental science as an independent discipline and incorporate it in all our courses as a critical skill for future employment of the learners, just like we do with communication skills and teamwork. 
"Climate change is an existential threat and the most important issue of all ... there are no grey areas when it comes to survival. Either we go on as a civilization or we don't. We have to change" (Thunberg, 2018). Educators have to evolve as the environment around them changes. Young leaders need not roll their eyes and march on without us. Sustainability requires societal change along with the wisdom to direct a more positive, sustainable future for generations yet to be born. Wherever we stand, let us acknowledge the interconnectedness and interrelationship of all living and non-living things; we have that framework (Otago Polytechnic, n.d. a). We do not need 'more' of anything; we do not have to wait. We do not have to work harder; the learning outcomes stay the same while the contexts differ. Our lofty vision must be bold enough to live beyond our tenure. We must adapt at a fervent pace because, as Bob Dylan sings, "the times, they are a changing."

Yury Zhukov is a Senior Lecturer at Otago Polytechnic Auckland International Campus. He is pursuing his interests in deliberative democracy and e-government at the University of Auckland where he is currently working on his $\mathrm{PhD}$ (Deliberation in Tertiary Education Policy). He has been working in tertiary education alongside other jobs for over fifteen years.

(D) https://orcid.org/0000-0001-9346-9139

Marianne Cherrington is a Senior Lecturer at Otago Polytechnic Auckland International Campus, studying Computer Science and Analytics. A lecturer in disruptive innovation, her research into machine learning feature selection algorithms applies in many fields, producing interesting collaborations with international partners in many disciplines and sectors.

(DiD https://orcid.org/0000-0002-1240-2010

\section{REFERENCES}

Air New Zealand. (2020, June 5). Sustainability. Retrieved from https://www.airnewzealand.co.nz/ sustainability

Air New Zealand. (n.d) Diversity \& inclusion - About air New Zealand. Retrieved from https://www.airnewzealand.co.nz/diversityand-inclusion.

Anthony, S. D., Viguerie, S. P., Schwartz, E. I., \& Van Landeghem, J. (20I8). 2018 corporate longevity forecast: Creative destruction is accelerating. Innosight. Retrieved from https://wwwinnosight.com/insight/creative-destruction

Ardern, J. (2020). Child Poverty Related Indicators. Retrieved from https://dpmc.govt.nz/sites/default/files/2020-07/child-povertyrelated-indicators-2020.pdf

Australasian Campuses Towards Sustainability. (n.d.). ACTS: About us. Retrieved from https://www.acts.asn.au/about-us

Barclays. (2020, 08 April). Education technology: Out with the old school. Retrieved from https://www.investmentbank.barclays. com/our-insights/education-technology-out-with-the-old-school.html

Blick, G., \& Comendant, C. (20।8). A circular economy for Auckland - scoping the potential economic benefits.

Carson, R. (2009). Silent spring. 1962.

Cherrington, M. (2019). Environmental Social and Governance Sustainability - Ka Mua, Ka Muri. Scope: Contemporary Research Topics (Learning \& Teaching), 8.

Climate Leaders Coalition. (n.d.). About. Retrieved from www.climateleaderscoalition.org.nz/about

Climate-X. (2020). Climate X Change. Retrieved from https://www.climate-X.org

Downes, C. (2018, May). Diversity and Inclusion Strategy to 2020. Air New Zealand. https://p-airnz.com/cms/assets/PDFs/DIStrategy-Document_2019.pdf

EduBits. (n.d.). Browse. Retrieved from https://edubits.nz/see-edubits/sustainability/

Ellen MacArthur Foundation. (2017). What is the circular economy? Retrieved from https://www.ellenmacarthurfoundation.org/ circular-economy/what-is-the-circular-economy

Frick, W. (2016, May II). Corporate Inequality Is the Defining Fact of Business Today. Harvard Business Review. 
Healy, J. (2019, June 10). Coffee culture that cares for our environment - we'll drink to that! Auckland Zoo. Retrieved from https:// www.Aucklandzoo.co.nz/news/coffee-culture-that-cares-for-our-environment-well-drink-to-that

Otago Polytechnic | Te Kura Matatini ki Otago. (n.d. a). Aka Whaika Māori: Māori strategic framework. https://www.op.ac.nz/ about-us/kai-tahumaori/maori-strategic-framework/

Otago Polytechnic. (n.d. b). I am capable. Retrieved from https://www.op.ac.nz/students/i-am-capable/

Rocket Lab. (2020). Join the pioneers. Retrieved from https://www.rocketlabusa.com/careers/positions/

Parker, T. (2020, June 27). Embracing the mobile mentality. The New Zealand Herald, p. C5.

Shareef, J., \& Harding, E. (2019, May). Product Stewardship Roadmap. Wellington, New Zealand: Ministry for the Environment. Retrieved from https://www.mfe.govt.nz/sites/default/files/group/Product\%20Stewardship\%20Doc_web_update.pdf

Soul Machines. (2018, September 18). Press: World's first digital teacher starts work teaching kids about energy. Retrieved from www.soulmachines.com/news/2018/09//8/press-worlds-first-digital-teacher-starts-work-teaching-kids-about-energy/

Sustainable Business Network. (2018). The Circular Economy Opportunity for Auckland. Sustainable Business Network.

The Economist. (2020, May 23). Countries should seize the moment to flatten the climate curve. The Economist. https://www. economist.com/leaders/2020/05/21/countries-should-seize-the-moment-to-flatten-the-climate-curve

Thunberg, G. (2018, November). Transcript of "The disarming case to act right now on climate change." TED: Ideas worth spreading. Retrieved from www.ted.com/talks/greta_thunberg_the_disarming_case_to_act_right_now_on_climate_change/ transcript?language $=$ en.

World Economic Forum. (2020a). Global Risks Report 2020. (Insight Report: I5th Edition). Retrieved from: www.weforum.org/ reports/the-global-risks-report-2020

World Economic Forum. (2020b). Shareable infographics. Retrieved from https://reports.weforum.org/global-risks-report-2020/ shareable-infographics/ 